\title{
Shot Transitions and Narrative Logic in Hitchcock's Rope
}

\author{
By Philippe Mather \\ Spring 2009 Issue of KINEMA
}

\section{SHOT TRANSITIONS AND NARRATIVE LOGIC IN HITCHCOCK'S ROPE}

Rope (1948, Alfred Hitchcock) belongs to a group of films including Lady in the Lake (1947, Robert Montgomery) which, in the history of classical Hollywood cinema, have experimented with the conventions of the continuity editing system, hoping perhaps to achieve a heightened spectatorial identification with the narrative, through a consistent use of the point-of-view shot for instance, or a seemingly uninterrupted long take with camera movement. These experiments are informative in that they tend rather to confirm the established system's apparent neutrality, its ability at "invisible" narration. I will argue that Rope's attempts at creating "hidden" cuts, chiefly through camera movement and close-ups of a jacket, result in defamiliarizing classical découpage: the "hidden" cuts become much more noticeable than those involving eyeline matches, for example.

Firstly, there are technological factors which play a role in determining the way in which a film may tell a story. The alternation in Rope between hidden cuts and "ordinary" straight cuts is a result of such factors: $35 \mathrm{~mm}$ Technicolor film magazines contained 952 feet of film, a little more than ten minutes worth, and the standard for projection reels is twice that amount, about 20 minutes. Therefore, the transitions required by the change of projection reels is handled through ordinary straight cuts, in order to avoid any potentially jarring jump cut effect that might arise from an approximate synchronization job by the projectionist. Rope has five projection reels, and the four cuts in question are easily identifiable thanks to the reel change marks visible in the top right corner of the frame, a few seconds prior to the end of each reel. As for the transitions required exclusively by the change of film magazines, of which there are five instances, they are accomplished with relatively obtrusive camera movements, until the screen blacks out for a second on a character's back. This adds up to 9 cuts. There are three additional cuts, in the first and last projection reels, varying in degrees of visibility, for a total of 12 cuts, or 13 takes in Rope.

Certainly, this is a far cry from the myth of the one take film which has kept circulating through the years. For example, in his 1955 study Le cinéma, Henri Agel writes: "Everything here has been shot with a single camera movement, in an absolute refusal to break up the space. There is only one shot in the entire film: the camera follows the characters though the various rooms of the apartment where the action takes place, without there being the slightest fragmentation" (45) (translation mine). Reading more critical reviews of the film reveals that when the existence of separate long takes is acknowledged, the five conventional straight cuts are rarely ever mentioned. They receive no mention in the Hitchcock/Truffaut interview book where, paradoxically perhaps, only the more noticeable hidden cuts are described (179-184).

This lack of precision is all the more surprising when one considers that Claude Chabrol and Eric Rohmer had already correctly identified the strategy of alternating cuts in Rope in 1957, less than ten years after the film's initial release (1948). In their early study of Hitchcock's films, they state: "Every other transition is accomplished on the back of a jacket. The rest of the time, eyeline matches are used, thereby cheating literally, if not figuratively, for it is these latter cuts which end up being less noticeable" (94). In a footnote, Chabrol and Rohmer go on to explain that since the precise synchronization required from projectionists for the hidden cuts could not be reasonably guaranteed, this led to the use of classical reverse-shots every 600 meters or so, that is, at each change in projection reels.

The logic behind the one-take idea appears to be not so much narrative identification, but rather a demonstration of technical virtuosity, of showmanship. Hitchcock himself admitted to Truffaut that he "undertook Rope as a stunt" (179). According to Donald Spoto, Hitchcock sought not only to impress his peers, but especially to prove to David Selznick that his idea could work (300). In The Classical Hollywood Cinema, David Bordwell also points out that "[d]uring the 1940s . . . there was something of a competition to see how complicated and lengthy the cinematographer could make his tracking shots" (21). Films such as Rope, 
Lady in the Lake, Casbah (1948, John Berry), Dark Passage (1947, Delmer Daves) and Gun Crazy (1949, Joseph H. Lewis) were all produced during this period.

To explain the apparent paradox in the perception of the shot transitions in Rope, I will appeal chiefly to the logic of narrative causality, and the impact of historically established filmic codes. Christian Metz, in Volume 2 of his Essais, explains that one reason straight cuts do not attract any attention is that "in classical découpage, the straight cut is most often used when punctuation is refused. The straight cut is meant to signal . . . the very unfolding of the discursive chain. Thus, the viewer barely notices it. . . . Today, we are so familiar with montage that no one would ever think of qualifying such an ordinary and general manipulation as a form of trucage (or special effect)" $(123,189)$ [translation mine].

The status of "special effect" is perhaps precisely what the hidden cuts were seeking to attain. They would then benefit from the simultaneous phenomenon of calling attention to the apparatus, or showing off, and justifying it through some form of narrative motivation. The semi-reflexive status of the trucage may in fact be crucial in justifying the single-take/camera movement project. Indeed, Hitchcock himself recognized that in some ways, Rope could be considered as little more than an exercise in reframing: "The mobility of the camera and the movement of the players closely followed my usual cutting practice" (Truffaut, 180). Therefore, the only way to make the audience notice and appreciate the stunt would be through the virtuosity of the hidden cuts, now recognized as not completely hidden. This simultaneous forwarding of technical brilliance and effacement via narrative causality represents the ideal of the special effect. The main thing is to avoid spoiling the viewer's special rapport with the fictional world in a gratuitous fashion. As Bordwell points out in Narration in the Fiction Film, "the use of technique must be minimally motivated by the characters' interactions [or]. . . justified by generic convention" (162).

Just as the straight cut usually signals a refusal of punctuation, the fade to black represents one of the strongest extrinsic norms in fictional cinema. In his history of film style and technology, Barry Salt observes that in D. W. Griffith films produced circa 1910, we see the "beginning of the convention that a fade-out represents a time lapse between shots. By 1912 this usage was beginning to become common" (121). I am arguing that the hidden cuts in Rope have an ambiguous narrative function: they are caught somewhere in between the trucage and the fade to black. The fade out effect of these transitions is unfamiliar, because they are not exactly fade outs, but resemble them, thus the confusion. Perhaps, it was hoped that the darkened screen might call attention to the technical stunt, but without being too distracting: the neutrality of a totally black frame would somehow ensure a smooth transition. I am assuming however, that a dark screen is far from neutral, and that these transitions' resemblance to the fade-out is particularly distracting in view of the fade-out's strength as a code in the history of narrative film. Visually, the film is temporarily interrupted: there is a moment of non-vision, of visual silence which suggests an act of temporal demarcation all the more strongly that there are only five such moments over a period of 80 minutes, and that these moments are spread out fairly evenly, like breaking a novel into several chapters.

In addition, the hidden cuts also fail as trucage, because the motivation is too weak: it is neither tied to generic conventions, nor does it involve a character's point-of-view, for example. The only possible type of motivation would be artistic, but as Bordwell points out, "the classical cinema does not encourage the film to cultivate idiosyncratic intrinsic norms" $(1985 \mathrm{a}, 164)$. This means that artistic motivation, in this style of filmmaking, still needs a minimal amount of narrative justification. In Rope, the hidden cuts cause the viewer to wonder what these close ups of a character's jacket are all about. In fact, it appears that the motivation is not so much artistic as it is strictly the result of technical considerations, which is largely irrelevant as regards the organization of a narrative's cause and effect chain.

In terms of its manipulation of the pro-filmic space, the most interesting hidden cut in Rope is the third one, situated halfway in the third projection reel, right in the middle of the film, close to the 44-minute mark. James Stewart is having a few words with John Dall, expressing his concern over the inexplicable absence of David, who was strangled at the start of the film. The two men are shown in a medium shot, standing at the entrance to the living room (figure 1). Stewart is facing the camera, on the left side of the screen, where the living room is located. Dall has his back to the camera, and is standing on the right side of the screen, where the hallway leads into the kitchen. The camera quickly dollies in to a close-up of Dall's jacket, thus creating the illusion that Dall is moving leftward, when we know full well that he is heading for the kitchen, which 


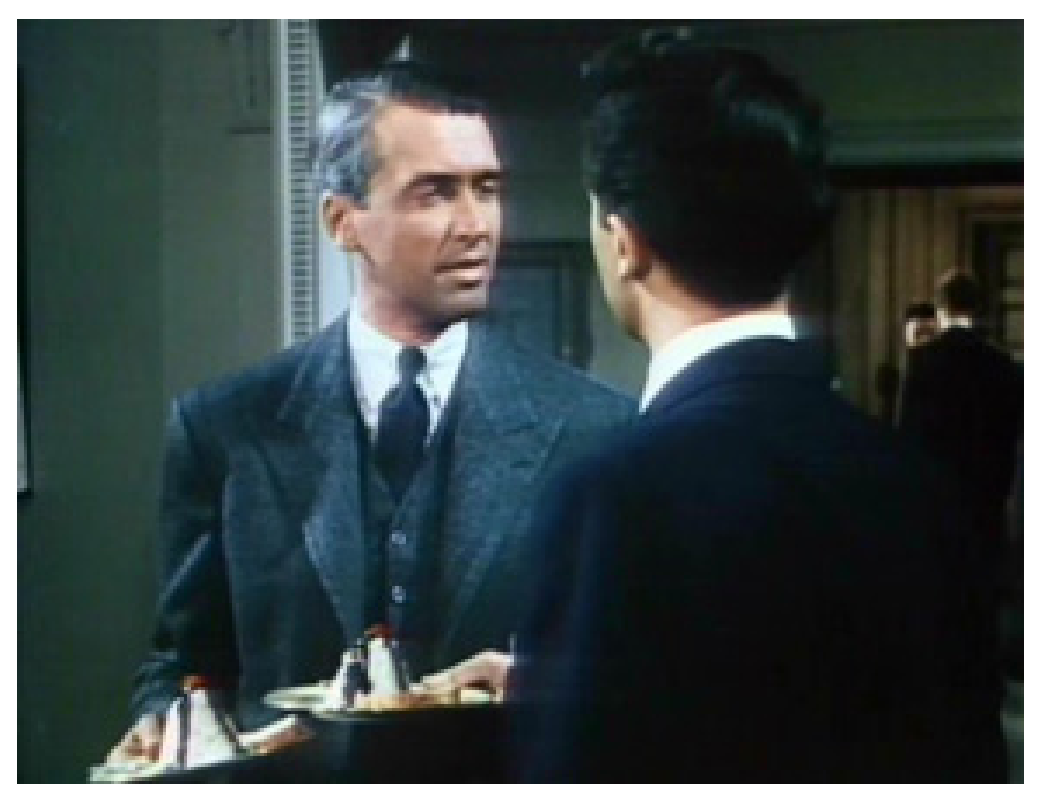

Figure 1: Rope (dir. A. Hitchcock, 1948)

is on the right side. But after the "hidden" cut on Dall's back, he continues to move leftward, as though he were performing a right-to-left wipe (figure 2). When he has left the frame, Stewart is now standing on the right, and on the other side of the entrance to the living room, where Dall was supposed to be.

There has been a "magical" 100-degree shift in the diegetic space, and yet it goes by relatively unnoticed. I would say there are basically three reasons that can explain this phenomenon:

1) John Dall's uninterrupted movement from right to left allows him to exit the frame less obtrusively than if he had to exit to the right, after having appeared to move to the left, thanks to the camera movement towards him. This resembles what Bordwell describes as editing for directional continuity: "If a character or vehicle is moving left to right in shot 1 , it should continue to do so in shot $2 "(1985 \mathrm{~b}, 57)$. In this scene from Rope, the vertical line of the wall behind Stewart's left shoulder works as an additional visual element linking the two different perspectives.

2) The moment of non-vision, of complete darkness, enhances the moving camera's ability to hide the manipulation of space via the graphic directional continuity. Despite the right-to-left wipe created by the moving character, it is the obstructed view which prevents us from noticing the background, added to which the close up of the jacket pulls us into the foreground. Once the dark jacket has been removed, we are presented with a fait accompli, not suspecting that even though James Stewart is at a similar distance from the camera before and after the transition, the space behind him has been altered. Also, the hidden cut's slight narrative ambiguity, specifically the temporal confusion created by the association with the fade to black, further distracts the viewer's attention away from questions of spatial verisimilitude.

3) The spectator is strongly encouraged to focus on the ongoing conversations, as John Dall's character is immediately replaced by Mrs. Wilson. James Stewart teases her, and the couple immediately moves to the right, followed by the camera, thus effacing any possible doubt we might have concerning spatial cues. It is also common practice in the classical Hollywood style to use dialogue overlaps, i.e. to create continuity between shots by cutting to the listener while the speaker carries on with the line of dialogue. In this case, James Stewart talks during the moment of darkness, though the spatial characteristics of his voice change: there is a stronger emphasis on the lower frequencies. It would seem that the sound technicians could not match the sound characteristics from one shot to the next, which is not crucial if intelligibility is maintained.

Rope demonstrates how formal innovations in the classical Hollywood cinema were risky ventures. An alternative would be to consider practices which deliberately set themselves in opposition to continuity 
editing. However, certain genres and narrative devices, for instance comedy and dream sequences, indicate how the classical style can justify innovative techniques. On the subject of spatial and temporal ambiguity, Bordwell offers this remark: "Momentary disorientation is permissible only if motivated realistically . . . [that is] when it conveys disorienting story situations" (1985a, 163). More interesting is his contention that cheat cuts (those cuts involving slight changes in body positions) indicate how "the spectator's cognitive processes rank cues by their pertinence to constructing the ongoing causal chain of the fabula" (1985a, 165). In other words, spatial and temporal cues are ranked according to their relevance to the ongoing story, which means their ability to enhance our identification with the characters and to construct a plausible cause-andeffect chain of events. This psychological requirement of classical cinema is a helpful way of establishing a hierarchy of perceptual cues. In the scene analyzed above, our need to identify with James Stewart's character overrides spatial verisimilitude. If he doesn't look surprised, why should we? It appears that the hidden cuts in Hitchcock's film do not function as a remarkable special effect, and that they only risk being slightly annoying.

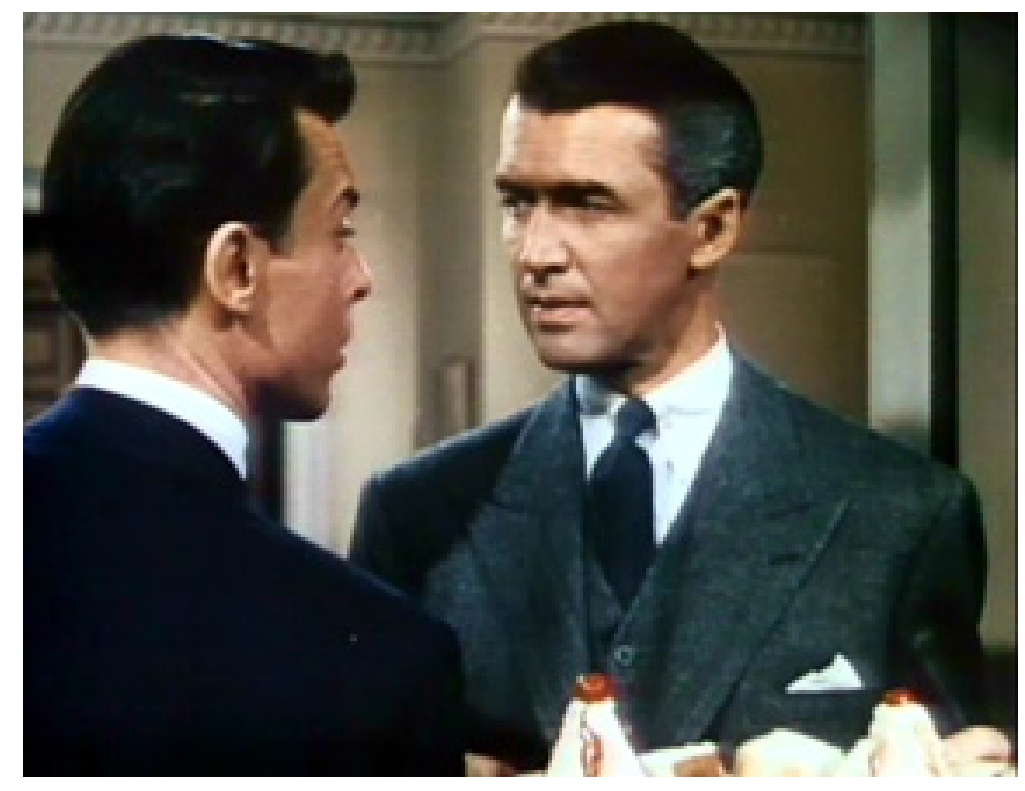

Figure 2: Rope (dir. A. Hitchcock, 1948)

\section{References}

\section{Literature}

Agel, Henri. Le Cinéma. Paris: Casterman, 1954.

Bordwell, David. 1985a. Narration in the Fiction Film. Madison: University of Wisconsin Press. 1985b. The Classical Hollywood Cinema. New York: Columbia University Press.

Chabrol, Claude et Eric Rohmer. Hitchcock. Paris: Editions Universitaires, 1957.

Metz, Christian. Essais sur la signification au cinéma, tome II. Paris: Editions Klincksieck, 1972.

Salt, Barry. Film Style and Technology: History and Analysis. London: Starword, 1983.

Spoto, Donald. The Dark Side of Genius: the Life of Alfred Hitchcock. Boston: Little, Brown and Company, 1983.

Truffaut, François. Hitchcock. New York: Simon and Schuster, 1984. 


\section{Author Information}

Philippe MATHER is Associate Professor of Media Studies at Campion College, University of Regina (Saskatchewan, Canada). He has published in journals including Cinémas, Science-Fiction Studies, Historical Journal of Film, Radio and Television, Extrapolation, and Cinémathèque. His areas of research

include the films of Alfred Hitchcock, film music, the science-fiction genre and the photojournalistic work of Stanley Kubrick. 